Family Medicine and Community Health

\section{Communities and service providers address access to perinatal care in postconflict Northern Uganda: socialising evidence for participatory action}

To cite: Belaid L, Atim P, Atim E, et al. Communities and service providers address access to perinatal care in postconflict Northern Uganda: socialising evidence for participatory action. Fam Med Com Health 2021;9:e000610. doi:10.1136/ fmch-2020-000610
Check for updates

(c) Author(s) (or their employer(s)) 2021. Re-use permitted under CC BY-NC. No commercial re-use. See rights and permissions. Published by BMJ.

${ }^{1}$ CIET/ PRAM Family Medicine, McGill University, Montreal,

Québec, Canada

${ }^{2}$ Public Health, Gulu University, Gulu, Uganda

${ }^{3}$ Maternal and child health, Nwoya Health District, Nwoya, Uganda

${ }^{4}$ St Mary's Lacor Hospital, Gulu, Uganda

${ }^{5}$ Family Medicine, McGill University, Montreal, Québec, Canada

${ }^{6}$ Preventive and social medicine, University of Montreal, Montreal, Québec, Canada

${ }^{7}$ Universidad Autónoma de Guerrero, Centro de Investigación de Enfermedades Tropicales, Acapulco, Mexico

Correspondence to

Dr Loubna Belaid;

Ibelaid@ciet.org

\section{ABSTRACT}

Objectives Describe participatory codesign of interventions to improve access to perinatal care services in Northern Uganda.

Study design Mixed-methods participatory research to codesign increased access to perinatal care. Fuzzy cognitive mapping, focus groups and a household survey identified and documented the extent of obstructions to access. Deliberative dialogue focused stakeholder discussions of this evidence to address the obstacles to access. Most significant change stories explored the participant experience of this process.

Setting Three parishes in Nwoya district in the Gulu region, Northern Uganda.

Participants Purposively sampled groups of women, men, female youth, male youth, community health workers, traditional midwives and service providers. Each of seven stakeholder categories included 5-8 participants in each of three parishes.

Results Stakeholders identified several obstructions to accessing perinatal care: lack of savings in preparation for childbirth in facility costs, lack of male support and poor service provider attitudes. They suggested joining saving groups, practising saving money and income generation to address the short-term financial shortfall.

They recommended increasing spousal awareness of perinatal care and they proposed improving service provider attitudes. Participants described their own improved careseeking behaviour and patient-provider relationships as short-term gains of the codesign.

Conclusion Participatory service improvement is feasible and acceptable in postconflict settings like Northern Uganda. Engaging communities in identifying perinatal service delivery issues and reflecting on local evidence about these issues generate workable community-led solutions and increases trust between community members and service providers.

\section{INTRODUCTION}

Every year, several hundred thousand women die from complications during pregnancy

\section{Key point}

Question: this study tested the feasibility and ac ceptability of participatory codesign of interventions to improve access to perinatal care services in a postconflict setting.

- Finding: this study illustrates the steps involved, their feasibility and acceptability. It suggests that three converging processes might improve careseeking behaviour and, in turn, perinatal outcomes: (1) learning and reflecting on evidence, (ii) raising awareness and taking actions and (3) transition from distrust to confidence.

- Meaning: Engaging stakeholders in generating and reflecting on local evidence is feasible and improves trust between community members and service providers.

and childbirth worldwide, and more than $90 \%$ of these deaths occur in low-income countries. ${ }^{1}$ In Uganda, the average 2016 maternal mortality ratio was 336 per 100000 live births, ${ }^{2}$ with northern Uganda among the highest (610 per 100000 live births). ${ }^{3}$

The civil war in Northern Uganda (19862006) displaced more than $90 \%$ of the population of that region. ${ }^{4}$ Armed conflict disrupted community and health service functioning, with consequent deterioration of maternal health. ${ }^{4}$ The 2016 Uganda demographic health survey reported that $87 \%$ of women in the Northern region had at least one problem accessing health services. ${ }^{2}$ Access to obstetric care reliably predicts maternal and perinatal mortality. 6

A large literature suggests that participatory interventions can positively impact maternal health. ${ }^{7-12}$ A 2015 review of interventions 
that included community mobilisation reported an increase in antenatal care use and childbirth in health facilities. ${ }^{9}$ A 2019 systematic review showed that community-led interventions can reduce inequities in coverage and can improve health-seeking behaviours. ${ }^{13}$ Community engagement in designing, implementing and evaluating interventions seems to increase access to perinatal services and improve health-seeking behaviours, although it is quite unclear how it improves maternal outcomes. Several authors call for more evidence to understand the processes underlying this approach. ${ }^{14-17}$

This study describes the codesign of interventions to improve access to perinatal care services in postconflict Northern Uganda. It has three objectives. It explores community and service provider views on access to perinatal care. It generates evidence for dialogue to improve access to perinatal services. And, in the context of feasibility and acceptability, it seeks to understand how women, their communities and service providers experience their participation in codesign.

\section{METHODS}

\section{Overview}

Participatory research is the science of partnerships underlying research and concerned with ownership of research processes and products. It advocates cocreation of knowledge to codesign interventions benefiting community members. ${ }^{18}$ The process promotes colearning and an empowering interaction that produces and uses local evidence for health promotion and community development. ${ }^{19}$ A protocol called Socialising Evidence for Participatory Action (SEPA), partner researchers with communities and services to codesign solutions to service delivery issues, engaging stakeholders in various stages of research-to-action. ${ }^{20}$ This sequence of steps engaged women and other stakeholders in Northern Uganda to codesign improvements in perinatal care access. Fuzzy cognitive mapping (FCM) collated stakeholder views on obstructions to accessing perinatal care. Focus group discussions clarified the concepts and lexicon that emerged during mapping. A baseline survey quantified perinatal outcomes. Deliberative dialogue sessions listed potential actions to overcome the obstacles to access perinatal services. The most significant change (MSC) narratives collated individual stories to explore the impact as experienced by participants (figure 1).

\section{Study setting and research team}

The initiative took place in Nwoya district (estimated population 133,506) in the Gulu region of Northern Uganda in 2019-2020. ${ }^{21}$ It involved three randomly selected parishes, the administrative unit below subcounties, each with a population of around 10000 people. The main ethnic group in Nwoya is Acholi and the main religion is Catholic. More than $80 \%$ of the population is rural and depends on subsistence agriculture. ${ }^{5}$ Many women living in these rural areas have low education levels, high

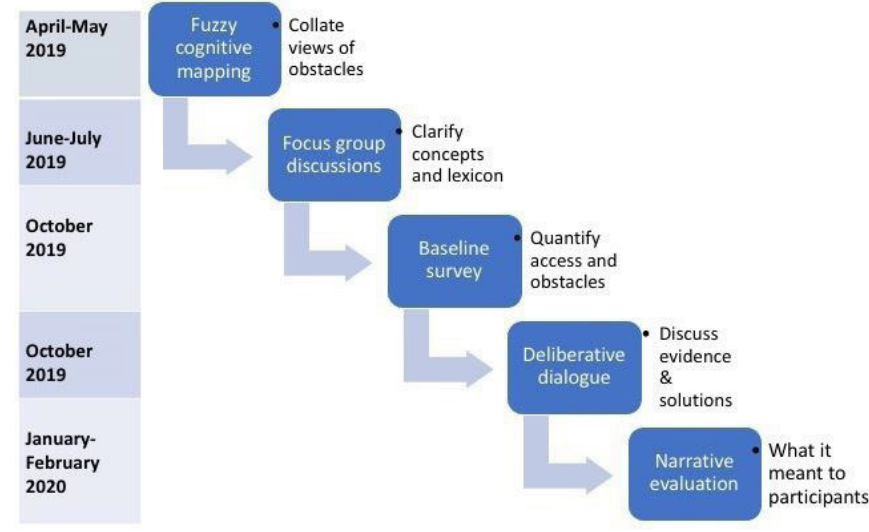

Figure 1 Data collection steps.

levels of poverty and face a patriarchal society. One consequence is that they are less likely to use health services or to benefit from health promotion programmes. ${ }^{2}$

Public, private not-for-profit (predominantly faithbased) and private for-profit providers offer perinatal care to the residents of Nwoya. In 2001, the Ugandan government waived clinic admission fees to reduce obstacles to primary healthcare. People still have to pay for all procedures and materials; however, professional midwives charge user fees. ${ }^{22}$ In 2010, the Ministry of Health banned homebirths by traditional midwives.

PA is a local female researcher who led activities on the ground. EA is a local community midwife trained in qualitative research. BO is a graduate student and trained in qualitative research. PA, EA and BO are Acholi and have significant experience working with rural communities. LB is a Canadian female anthropologist of African ancestry.

\section{Data collection}

\section{Fuzzy cognitive mapping}

Cognitive mapping is a graphic display of knowledge about causes and outcomes. ${ }^{23}{ }^{24}$ It depicts how people see an issue and helps to frame actionable elements of an intervention. To build a cognitive map, small groups or individuals identify causal factors and links between factors. They weight each link to reflect its importance (the reason it is called 'fuzzy'). In this case, cognitive mapping collated views on obstructions to access perinatal services. NA and LB purposively identified seven stakeholder groups: (1) women of childbearing age, (2) men, (3) female youth (18-25 years old), (4) male youth, (5) community health workers, (6) traditional midwives and (7) service providers (nurses and midwives involved in perinatal care). PA and EA invited participants from each stakeholder group, who provided informed consent and resided in or served one of the study parishes.

PA and EA met each stakeholder group of 5-8 participants separately, in one group per stakeholder category and per parish. PA moderated the sessions in the Acholi language, and EA took notes. Each session lasted around 2 hours in a public space (near a school, church). PA asked the question: What prevents you from accessing perinatal 

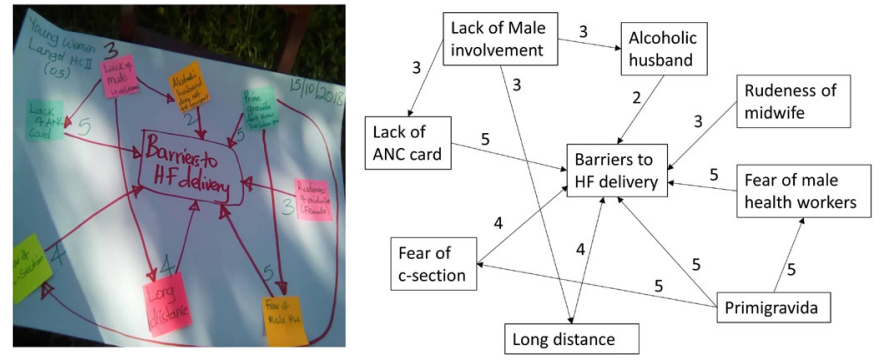

Figure 2 Drawing and digitised map.

services? Each participant shared their answers on post-it stickers. PA placed the concepts on a large blank sheet of white paper. She invited participants to sort the concepts, to reduce overlap and to cluster similar concepts. Participants then indicated the direction of links between concepts and weighted each link, rating it between one as the weakest and five as the strongest. The facilitator did not record the sessions but took a digital photo of each map for subsequent analysis (figure 2).

\section{Focus groups discussion}

PA and EA conducted focus groups in Acholi to clarify and to unpack the concepts mentioned in the cognitive mapping. PA and EA invited participants by phone and in person, constituting 15 stakeholder groups from participants who built the cognitive maps. The stakeholders were women, female youth, men, male youth and community health workers. Each group included 5-8 participants. Each group met separately, PA following a pretested focus group guide. Each session lasted 1 hour. They did not digitally record the discussions to encourage participants to speak freely.

\section{Baseline survey}

LB adapted an e-questionnaire from similar work in Nigeria, ${ }^{25}$ covering the study population characteristics, risk factors and outcomes for the most recent pregnancy. EO pretested the e-questionnaire among women who had a birth in the past 2 years. EO and BO used GPS and cellular-enabled android tablets and $\mathrm{ODK}^{26}$ software to administer the questionnaire in households in both intervention and control parishes. ODK software collects data offline using mobile devices in remote areas. With cellular connectivity, data are transferred to our server in Uganda, from where they can be accessed and managed by internet.

\section{Deliberative dialogue}

After analysing the cognitive maps and focus group data, PA and EA invited the stakeholder groups to participate in deliberative dialogue. In this evidence-focussed discussion, stakeholders listen to one another's interpretation of the findings. The goal is not to reach consensus but to understand how each stakeholder sees the issues, to reflect on this and to find ways forward. The usual outcome is a shortlist of what can be done and who might be involved in each solution. ${ }^{27} \mathrm{PA}$ and EA conducted three dialogue sessions in Acholi with the same stakeholder groups from the cognitive mapping and focus groups. Between 15 and 20 participants joined each deliberative dialogue session. Each dialogue lasted 3 to 4 hours. Housed in health facilities in each parish, stakeholders discussed the evidence and listed potential actions to improve access to perinatal services. They identified several ways towards solutions. $\mathrm{BO}$ and $\mathrm{EO}$ took notes and fully transcribed them in word documents.

\section{MSC narratives interviews}

MSC is a narrative evaluation tool that allows researchers to collate stories about how intervention changes participants' lives. The tool identifies intended and unexpected outcomes and can provide insight into the mechanism of impact in the participant's own words. ${ }^{28} 29$ This study used MSC to explore the value of participation for those engaged in the process. PA and BO collated 20 individual stories from each stakeholder group in Acholi. PA invited participants to narrate a story reflecting the impact of this study on their lives. Each session lasted about $30 \mathrm{~min}$ (table 1).

\section{Data management and analysis}

LR-R digitised the fuzzy cognitive maps using yEd software. ${ }^{30}$ IS applied transitive closure, a mathematical algorithm that places each causal relationship in the context of all possible relationships in the map, to convert maps into knowledge networks for each stakeholder group. ${ }^{31}$ Thematic analysis began with condensing the list of all factors mentioned in the maps into fewer categories. IS aggregated weights from the average maps for each stakeholder group into the categories and calculated the cumulative influence as the sum of all the weights in each category. In the final map, IS scaled the cumulative influences dividing them by the maximum cumulative influence in the map to obtain values between 0 and $1 .{ }^{32}$

$\mathrm{PA}, \mathrm{EA}$ and BO transcribed and translated the focus groups, the notes from the deliberative dialogues and the MSC narratives to English. LB used an inductive approach to design the coding structure; she and LR-R coded the data manually and drafted narrative reports from the three data collection methods. LB analysed the data for each parish and compared their pattern to identify similarities and contrasts.

The baseline survey provided baseline indicators, response rates and variances for calculating sample size for a subsequent proof-of-impact (not reported here). EO tested the handset tablet's implications, including training, quality control, data collation and cleaning. This survey was not powered to measure impact and, on its first round, settled the feasibility and acceptability issues.

IS and LR-R produced summary maps of the three most substantial relationships from the FCM and survey and used colours to differentiate categories to facilitate the discussions with the participants during the dialogue sessions. The size of the factors and thickness of the arrows were proportional to their influence on the map. 
Table 1 Data collection and stakeholder groups

\begin{tabular}{|c|c|c|c|}
\hline Data collection & Gender and age & Number & Selection criteria \\
\hline $\begin{array}{l}\text { Fuzzy cognitive } \\
\text { mapping }\end{array}$ & $\begin{array}{l}\text { Men and women } \\
\geq 18 \text { years of age }\end{array}$ & $\begin{array}{l}\text { 5-8 participants for each } \\
\text { group } \\
\text { Total: } 21 \text { sessions }\end{array}$ & $\begin{array}{l}\text { Separate sessions with homogenous groups } \\
\text { of men (youth/ adult), women (youth/ adult), } \\
\text { traditional midwives, service providers in each } \\
\text { parish }\end{array}$ \\
\hline $\begin{array}{l}\text { Focus group } \\
\text { discussions }\end{array}$ & $\begin{array}{l}\text { Men and women } \\
\geq 18 \text { years of age }\end{array}$ & $\begin{array}{l}5-8 \text { participants } \\
\text { Total: } 15 \text { groups }\end{array}$ & $\begin{array}{l}\text { Separate sessions with homogenous groups } \\
\text { of men (youth/ adult), women (youth/ adult), } \\
\text { traditional midwives, service providers in each } \\
\text { parish }\end{array}$ \\
\hline Deliberative dialogue & $\begin{array}{l}\text { Men and women } \\
\geq 18 \text { years of age }\end{array}$ & $\begin{array}{l}\text { 15-20 participants } \\
\text { Total: } 3 \text { sessions }\end{array}$ & $\begin{array}{l}\text { Heterogeneous sessions with participants } \\
\text { who joined the cognitive mapping and focus } \\
\text { groups from each stakeholder groups }\end{array}$ \\
\hline Household survey & $\begin{array}{l}\text { Women } \\
\geq 18 \text { years of age }\end{array}$ & $\begin{array}{l}\text { Women who delivered in the } \\
\text { last } 2 \text { years in intervention and } \\
\text { control parishes }\end{array}$ & \\
\hline
\end{tabular}

Based on the notes taken in each mapping session, LB wrote the narrative report that provides the basis for this article.

\section{RESULTS}

Table 2 shows results of the household baseline survey, an electronic questionnaire administered to women in all three parishes. The intersecting disadvantages of women are reflected in the high proportion with only primary or no education, the proportion living in male-headed households, the tiny proportion of women involved in decisions about land and the proportion who paid for their own perinatal care.

\section{Obstacles to access perinatal services}

Cognitive mapping identified a lack of birth preparedness and poor service providers' attitude as the two most prominent obstructions for accessing perinatal services. Except for service providers, all groups saw a lack of male involvement as the third most influential barrier (table 3 ). Table 4 summarises the strategies generated to overcome these obstacles.

\section{Lack of birth preparedness}

Participants explained lack of birth preparedness as a financial issue, having insufficient resources set aside to access health services for pregnancy and childbirth.

Lack of birth kits like basins make women fear to go to the health center (FGD\#2, female youth). People who go to deliver may not have basic delivery kits, such as a flask, baby's clothes, basin, and maternity dress. This makes work difficult for them (FGD \#3, adult, men).

\section{Lack of male involvement in perinatal care}

While most households were headed by men (57\%), they did not contribute enough to providing financial support to their spouses for perinatal care. Men recognised their lack of support to their spouses in the FCM and focus groups.

\section{Poor health service's provider attitude}

Poor service provider attitudes included verbal and physical abuse of pregnant women. Focus groups described the experience of physical abuse during labour. They depicted several forms of abuse, including being ignored, denied care, leaving women delivering alone, being yelled at and using inappropriate language.

Health workers are rude, and sometimes they are tired, so they raise their voice at mothers. Women also do not prepare for their deliveries, making health workers rude because they lack birth kits. Some health workers despised and undermined, mostly unkempt dirty women who come for deliveries. Some women come from poor families; they go to health centres without all birth kits so that health workers will be rude (FGD \#7, male youth).

Verbal abuse was prominent during prenatal care, especially when a pregnant woman did not attend with her spouse. Focus groups identified a lack of birth preparedness as the underlying cause of abuse of women in health facilities.

\section{Solutions to improve access to perinatal services}

The deliberative dialogue identified local and feasible solutions to overcome each of the obstructions cited above to improve perinatal care access. The results of 
Table 2 Sociodemographic characteristics and pregnancy and childbirth outcomes

\begin{tabular}{|c|c|}
\hline Variables & $\begin{array}{l}\text { Results from the } \\
\text { survey }\end{array}$ \\
\hline Women interviewed & $\mathrm{n} 255^{\star}$ \\
\hline Age & $\overline{\mathrm{X}} 29.2$ SD8.4, (n255) \\
\hline Number of children & $\bar{X} 3.3$ SD2.1, (n248) \\
\hline Woman's education above primary & $37.8 \%(\mathrm{n} 249)$ \\
\hline Woman did not attend school & $4.4 \%(n 249)$ \\
\hline \multicolumn{2}{|l|}{ Household head } \\
\hline Husband & $68 \%(\mathrm{n} 255)$ \\
\hline Parents/parents in laws & $21 \%(\mathrm{n} 255)$ \\
\hline Women & $7 \%(\mathrm{n} 255)$ \\
\hline Other & $4 \%(n 255)$ \\
\hline Husband is a farmer or manual worker & $77 \%(\mathrm{n} 255)$ \\
\hline Women or family own agricultural land & $83 \%(n 255)$ \\
\hline More than two acres of land & $62 \%(n 204)$ \\
\hline Woman is involved in decisions on land & $6 \%(n 214)$ \\
\hline Woman is farmer or manual worker & $74 \%(\mathrm{n} 255)$ \\
\hline $\begin{array}{l}\text { Woman earns money from agricultural } \\
\text { work }\end{array}$ & $97 \%(\mathrm{n} 231)$ \\
\hline $\begin{array}{l}\text { Husband is main financial provider at } \\
\text { home }\end{array}$ & $57 \%(\mathrm{n} 255)$ \\
\hline
\end{tabular}

\section{Pregnancy and delivery}

The partner provided support during last $70 \%$ (n254) pregnancy

Who paid for transportation to health facility

\begin{tabular}{ll} 
Husband & $58 \%(\mathrm{n} 234)$ \\
\hline Women & $30 \%(\mathrm{n} 234)$ \\
\hline Family & $6 \%(\mathrm{n} 234)$ \\
\hline \multicolumn{1}{l}{ Volunteer/community member } & $6 \%(\mathrm{n} 234)$ \\
$\begin{array}{l}\text { Woman did not recognise any danger } \\
\text { signs during pregnancy }\end{array}$ & $38 \%(\mathrm{n} 250)$ \\
$\begin{array}{l}\text { Woman did not recognise any danger } \\
\text { signs during labour }\end{array}$ & $66 \%(\mathrm{n} 249)$ \\
$\begin{array}{l}\text { Woman did not have antenatal care } \\
\text { Delivered in a health facility }\end{array}$ & $2 \%(\mathrm{n} 256)$ \\
\hline $\begin{array}{l}\text { Woman experienced any form of mental/ } \\
\text { verbal abuse at home }\end{array}$ & $90 \%(\mathrm{n} 250)$ \\
\hline $\begin{array}{l}\text { Woman experienced physical violence } \\
\text { Wom (n254) }\end{array}$ & $19 \%(\mathrm{n} 254)$ \\
\hline
\end{tabular}

${ }^{*} \mathrm{n}$ refers to the number of women answering the household baseline survey. each dialogue session converged, although consensus was not intentional or required. Participants saw lack of birth financial preparedness as an obstacle that individual might manage independently. Health service provider attitudes and the lack of male support were obstacles that need more collective actions.

Tackling shortfall of financial resources for birth preparedness For the lack of birth preparedness, joining saving groups, practising self-saving and engaging in activities to generate incomes were the communities' three solutions. Saving groups are groups (often women, around 15-30 individuals) that pool its savings to have a lending source. Members make saving contributions to the pool and borrow from it. These groups aim to improve access to financial services to their members. Mostly women engage in these groups to pay their medical expenses, school fees for their children, grow their farming activities or start an activity to generate income.

I see most people here have saved some money apart from their domestic activity. Some people are in savings groups. The savings groups are very good and can help people in emergency times to borrow money to help them (DD \#2, service provider).

We need to have a multi-approach to poverty at home so that families can handle emergencies like labor by farming, growing crops. Each family must have an activity bringing money into their hands (DD \#2, service provider).

Raising patient's voices and increasing mutual understanding with service providers

To address the service provider's attitude, the participants suggested three solutions: (1) voicing complaints through the health management committee, (2) raising awareness on patient's rights and (3) mutual understanding between service providers and communities through selfreflection on their respective attitudes.

The health workers, with the patients, should be taught to know what to do and to understand each other (DD \#2 traditional midwife).

The patients could report the rude health workers to the facility management committee to negotiate, come up with a dialogue for the patient treated rudely, and the health workers to reconcile. Some patients also have a bad approach (DD \#2 service provider).

Table 3 The most influential obstructions to accessing perinatal care

\begin{tabular}{|c|c|c|c|c|c|c|c|}
\hline Causes & $\begin{array}{l}\text { Service } \\
\text { providers }\end{array}$ & CHWs & $\begin{array}{l}\text { Traditional } \\
\text { midwives }\end{array}$ & Men & Women & $\begin{array}{l}\text { Male } \\
\text { youth }\end{array}$ & $\begin{array}{l}\text { Female } \\
\text { youth }\end{array}$ \\
\hline Lack of birth preparedness & 1.00 & 1.00 & 1.00 & 1.00 & 1.00 & 1.00 & 1.00 \\
\hline Lack of male support & 0.00 & 0.13 & 0.26 & 0.20 & 0.14 & 0.15 & 0.24 \\
\hline
\end{tabular}

$\mathrm{CHW}$, community health worker. 
Table 4 Synthesis of strategies suggested by the communities and service providers

\begin{tabular}{|c|c|c|c|}
\hline $\begin{array}{l}\text { Main obstruction to } \\
\text { perinatal care }\end{array}$ & Strategies & Likely main effect & $\begin{array}{l}\text { Other effects } \\
\text { perceived }\end{array}$ \\
\hline $\begin{array}{l}\text { Lack of birth } \\
\text { preparedness }\end{array}$ & $\begin{array}{l}\text { Join saving groups } \\
\text { Practice self-saving } \\
\text { Income-generating activities }\end{array}$ & $\begin{array}{l}\text { Early prenatal check-ups } \\
\text { Increased in facility-based deliveries }\end{array}$ & \multirow{3}{*}{$\begin{array}{l}\text { Increased community } \\
\text { awareness } \\
\text { Bringing people } \\
\text { together and voicing } \\
\text { opinions in public } \\
\end{array}$} \\
\hline Lack of male support & $\begin{array}{l}\text { Raise awareness of men to } \\
\text { increase their involvement in } \\
\text { perinatal care }\end{array}$ & $\begin{array}{l}\text { Men saving money for facility-based } \\
\text { deliveries } \\
\text { Men accompanying their wives to the } \\
\text { health facility } \\
\text { Men provide more support for their wives } \\
\text { in the next pregnancy } \\
\text { Reduction in gender-based violence }\end{array}$ & \\
\hline $\begin{array}{l}\text { Poor service provider's } \\
\text { attitude }\end{array}$ & $\begin{array}{l}\text { Voice complaints through } \\
\text { health management committee } \\
\text { Raise awareness on patient's } \\
\text { rights } \\
\text { Mutual understanding } \\
\text { between health providers and } \\
\text { communities through self- } \\
\text { reflection on their respective } \\
\text { attitudes }\end{array}$ & $\begin{array}{l}\text { Improved provider and community } \\
\text { attitudes } \\
\text { Improved provider-patient relationships }\end{array}$ & \\
\hline
\end{tabular}

\section{Engaging men to promote cultural safe perinatal care}

They suggested engaging men in a safe perinatal programme to increase their support to their pregnant spouses. They proposed that the programme should be implemented at the community level through CHWs using visual tools.

Some people are told to prepare early, but they do not take that seriously, especially the men. They end up going into labor without equipment like clothes and basins. The men are the ones who should be taught most because it is hard for them to understand (DD \#2 traditional midwife).

I think that the sensitization should be done through CHW so that information reaches the men. Some men do not understand and often refuse to go to the health facility (DD \#2, man).

\section{Acceptability of participating in codesign}

Several months after the deliberative dialogue, PA and BO invited members from each stakeholder group to describe what their participation in codesign had changed in their personal lives using the MSC technique. The stories collected reflect how the project helped men, women, youth, community health workers, traditional midwives and other service providers to reflect on their attitudes and to improve access to perinatal care.

\section{Improvement in male's support and seeking care behaviours}

Some men mentioned that they went to the health facility with their spouses. Others described their intention to be more supportive of their spouses for the next pregnancy. Women reported going earlier to the health facility for pregnancy check-ups. As a result of this behavioural change, the service providers perceived an increase in early prenatal check-ups and facility-based childbirth.

I also didn't know about how a woman should prepare when going into labor, but I learned that I would prepare well if I get pregnant again. Previously, I used to start going for an antenatal checkup after six months of pregnancy, but I now know that a woman should go for an antenatal checkup as early as the first month of pregnancy (woman).

My participation in this project has helped me to learn so many things, for instance, about early preparation for delivery when my wife is pregnant. Previously, I used to relax until my wife started experiencing labor pain, but I know that the next time my wife gets pregnant, I would have to save enough money to buy equipment and clothes for my wife and my baby (youth male).

This project helped me a lot as a health worker in performing my duties at the health facility. More women are coming to deliver at this facility to deliver, and they come with all the necessary equipment for delivery, which has made our work easier. This has increased the number of women coming for antenatal care (service provider).

\section{Improvement in patient-provider relationships}

The project enabled communities and providers to reflect on their attitudes and take actions to improve their relationships.

After this program, I feel there is a change in how I handle the patients. I used to treat them rudely, but I learned to treat them in a friendly way after 
participating in this project. Most of them now talk positively about me when they go back to their community. The gap between patients and health workers has been narrowed significantly because of this project. The number of women coming to this health facility for antenatal care increased (service provider).

Previously, most of the members in this community, including myself, were fond of talking rudely to the health workers and negatively about them in the community especially when we come to the health facility and fail to get complete doses of medication for our illnesses, but I stopped that (youth male).

I feel that there has been a massive change in how we receive care at the health facility. Previously, the health workers used to be very rude to us patients, and they used to stop work early, but since the implementation of this project, I believe some actions were taken, which have made them start treating us well (woman above 25 years old).

\section{Increased community awareness of health}

The project supported stakeholder groups to work as agents for change through sharing local evidence generated from the project. This was an unexpected impact of the project. By participating in this project, the participants started to share and discuss what they learnt from this study with other community members.

While male youth engaged in discussions with their peers, older men advised their children. Community health workers and traditional midwives advised their neighbours. Service providers perceived this spread of information as a contributor to increasing community awareness on perinatal care.

Because of this project, I was able to learn so much information, which helped me to sensitize people in the community about health issues. I have been telling the younger men with whom I always hangout about the importance of supporting our wives, especially when they are pregnant, and to save some money that they would use during delivery (male youth)

I learned so many issues that I did not know before, which even empowered me to teach the women in the community about antenatal care and the need to deliver in a health facility. I always told pregnant women to prepare well for the delivery by buying all the necessary things for delivery so that the health workers find it easy to help them (Traditional midwife).

Following this project, I have been helped in my duty as a community health worker because most of the women used not to take my sensitization seriously, but when you people came and taught them the same things, they started respecting me. More women have started going to the health facility for antenatal care and delivery after the project came into place. The number of maternal deaths is very high in Uganda, but if projects like this one are in place, awareness would be increased in the communities, and those mortalities would be reduced (Community health worker).

\section{Bringing people together and hearing new voices}

The project strengthened the sense of belonging to the community, which stimulated three dynamics: (1) creating a safe space to share their experience and receive support from their communities, (2) freeing to express oneself and (3) voicing in public (table 4).

This project helped to remove shyness from me because previously, I used to fear to talk to the health workers about my health problem, but now, I am not afraid to talk to them (man).

My life has also changed in terms of public speaking. I used to stay mostly alone and in isolation, but the project kept bringing me together with other people in groups where we shared our views on many issues, and my shyness vanished. I am no longer afraid to attend public gatherings (male youth).

\section{DISCUSSION}

The cognitive mapping and focus groups identified influential obstructions to accessing perinatal services. These include lack of financial preparedness, poor service provider attitudes and lack of male involvement. The dialogue recommended increasing spousal awareness of perinatal care and improving service provider attitudes.

In the narrative evaluation, the seven stakeholder groups described a transformative experience that increased their health awareness and strengthened relations with service providers. Our study confirms the feasibility and acceptability of including both community and service provider views on perinatal care and on the obstacles to access perinatal services in this postconflict setting. Systematic reviews of other settings also identified a lack of financial resources for birth preparedness and male involvement and poor service providers' attitudes as obstacles to perinatal care access. ${ }^{33} 34$

After the deliberative dialogue, the researchers and local partners configured an intervention to improve male support and service provider attitudes based on the deliberative dialogue. They applied for funding for this intervention on a larger scale within Nwoya district. This intervention and its impact are the subjects of a separate report.

A key contribution of this project was the contextualisation of existing knowledge on perinatal care. The literature documents innumerable factors affecting access to perinatal services. The list is too long to be actionable in the short term. FCM identified and weighted the most influential factors in this setting. It included perspectives of seven stakeholder groups to ground this knowledge.

The literature on financial barriers suggests that system changes like universal free health coverage, voucher 
systems and cash transfer strategies. ${ }^{35} 36$ These demand financial and logistic resources along with long-term policy commitment, while cash transfers and voucher systems are rarely sustainable. ${ }^{35}{ }^{36}$ Our deliberative dialogue recognised the problem of financial shortfall and proposed local alternatives that could be sustainable. It suggested that women might join saving groups and income generation projects.

Addressing service provider attitudes is a challenge. A large literature suggests skill development for providers, quality improvement teams, mentorship and improved working conditions for staff as potential strategies. ${ }^{37}$ Our study engaged both communities and service providers in evidence-based respectful dialogue that helped both parties to reflect on their attitudes. The narrative evaluation indicates that this led codesign participants to change attitudes towards one other, increasing mutual understanding and respect.

Consistent with our findings, there is growing evidence that engaging men in perinatal care. ${ }^{38-40}$ A 2018 review of 13 male-inclusive interventions found a positive association with care-seeking and home care practices. ${ }^{38}$ The interventions included men as part of a broader community engagement. Interventions to increase male involvement should be designed and implemented with care to mitigate potential harmful effects on couple relationship dynamics. ${ }^{39}$ In our study, the deliberative dialogue made quite concrete suggestions, like male community health workers using visual tools to engage men in issues related to pregnancy and childbirth. In the next step of this project, not reported here, we will invite communities to discuss the visual tool's content.

Our study offers insights into three dynamics that might improve care seeking behaviour in postconflict and other settings: learning and reflecting on evidence, raising awareness and engaging in action and transition from distrust to confidence. A home visit programme in Northern Nigeria generated similar results after households reflected and discussed maternal risk factors and took actions to address them. ${ }^{25}$ Studies assessing women's group interventions in South Asia and Africa reported that women found learning through discussion and group reflection was a key to changing health seeking behaviours. ${ }^{41}$ A 2020 systematic review reported that participatory interventions using collective learning based on reflection and discussion had higher impact on health outcomes at the population level than did classroom teaching-learning style. ${ }^{42}$

The narrative evaluation reported individual participants in our deliberative dialogue experienced increased awareness, greater inclination to action and a feeling of empowerment. Deliberative dialogue was also an opportunity for stakeholder groups to hear each other's perspectives, increase mutual respect and search for ways to improve perinatal care access. The dialogue in our study was crucial in shifting community distrust to confidence, as participants took up perinatal services immediately after the dialogue and saw the impact on their decisions.
In Kenya, Zambia and South Africa, deliberative dialogues reportedly created a safe space to discuss family planning methods and promoted a mutual understanding of each stakeholder group's realities. ${ }^{43}$ Those dialogue sessions reported a sense of cohesion and, like our case, the authors found that participating in the dialogue was a transformative experience. ${ }^{43}$ In Tanzania, dialogue grounded social protection knowledge, raised awareness of children's protection and built community participation and ownership of the issue. ${ }^{44}$ In Uganda, Zambia and Mozambique, community dialogues triggered increased uptake of children's health services. ${ }^{45}$ Trust is a core tenet for any health system ${ }^{46}$ and, in conflict and postconflict settings, trust is more likely disrupted. ${ }^{47} \mathrm{~A}$ recent body of work advocates for participatory approaches in humanitarian crisis settings to increase trust between communities and service providers. ${ }^{48-50}$

\section{Limitations}

This study illustrates the process, feasibility and acceptability of participatory health service improvement in one postconflict setting. The impact thus far refers only to participants involved in the codesign. A follow-up project addresses implementation of the interventions resulting from the codesign and an assessment of their impact.

Translation from Acholi to English almost certainly lost some nuances of the FCM that keyed off the codesign. We tried to minimise this by convening focus groups to unpack the concepts that emerged during cognitive mapping. Deliberative dialogue was an opportunity to revisit the original cognitive mapping concepts in Acholi, involving many of the same stakeholders who generated the concepts in the first place.

The MSC evaluation focused on the changes experienced by the codesign participants. This narrative approach typically emphasises positive changes, although it can also identify unexpected and negative changes. We used the technique strictly to provide insight into the proof-of-concept of feasibility and acceptability to co-design participant's intervention without extrapolating the extent of the impact on access to services in general. This is the focus of additional research.

\section{CONCLUSIONS}

A participatory approach to service improvement is feasible and potentially helpful in postconflict settings like Northern Uganda. The SEPA protocol engaged communities and service providers in framing service delivery issues, quantifying them, discussing, reflecting on local evidence and recommending options. In the short term, this approach generated actionable strategies and increased trust between community members and service providers.

Twitter Loubna Belaid @loubna_belaid and Laura Rojas-Rozo @LauraRojasR2 Contributors NA designed and provided oversight to the study. LB directed the study. LB and NA drafted the manuscript. PA, EA and LB collected the data. IS, 
LR-R, LB analysed the FCM. LB and LR-R analysed the FGD. KZ, CZ, EO, MO, PB, JO, IWO, LB and NA participated in intellectual content analysis. All authors read and approved the final manuscript.

Funding This study was funded by Grand Challenges Canada (Grant number: GCC_R-ST-POC-1808-16505).

Competing interests None declared.

Patient consent for publication Not required.

Ethics approval This study followed ethical principles in the Declaration of Helsinki and ethical principles for research in post-conflict settings. Ethical approvals for this study were obtained from the Uganda National Council for Science and Technology (SS479) and the Faculty of Medicine of McGill University (FWA 00004545). Each participant provided informed verbal consent. The team treated all the information confidential. During group activities, participants received refreshments and a snack, but they were not paid for participation.

Provenance and peer review Not commissioned; externally peer reviewed.

Data availability statement Data are available upon reasonable request. The datasets used and analysed during the current study are available from the corresponding author on reasonable request.

Open access This is an open access article distributed in accordance with the Creative Commons Attribution Non Commercial (CC BY-NC 4.0) license, which permits others to distribute, remix, adapt, build upon this work non-commercially, and license their derivative works on different terms, provided the original work is properly cited, appropriate credit is given, any changes made indicated, and the use is non-commercial. See: http://creativecommons.org/licenses/by-nc/4.0/.

\section{ORCID iD}

Loubna Belaid http://orcid.org/0000-0002-0550-0560

\section{REFERENCES}

1 Alkema L, Chou D, Hogan D, et al. Global, regional, and national levels and trends in maternal mortality between 1990 and 2015 with scenario-based projections to 2030: a systematic analysis by the un maternal mortality estimation Inter-Agency group. Lancet 2016;387:462-74

2 Ministry of Health. Uganda demographic and health survey 2016. Key indicators reports. Kampala Uganda Bureau of Statistics, 2016.

3 Uganda Bureau of Statistics (UBOS). UDHS 2011 Uganda demographic and health survey. Kampala, Uganda: UBOS ICF International Inc, 2012.

4 UMo H. Health and mortality survey among internally displaced persons in Gulu, Kitgum and Pader districts, Northern Uganda. Kampala, Uganda: Ministry of Health, 2005.

5 Sengupta A, Calo M. Shifting gender roles: an analysis of violence against women in post-conflict Uganda. Dev Pract 2016;26:285-97.

6 Campbell OMR, Graham WJ, Lancet Maternal Survival Series steering group. Strategies for reducing maternal mortality: getting on with what works. Lancet 2006;368:1284-99.

7 Prost A, Colbourn T, Seward N, et al. Women's groups practising participatory learning and action to improve maternal and newborn health in low-resource settings: a systematic review and metaanalysis. Lancet 2013;381:1736-46.

8 Seward N, Neuman M, Colbourn T, et al. Effects of women's groups practising participatory learning and action on preventive and careseeking behaviours to reduce neonatal mortality: a meta-analysis of cluster-randomised trials. PLoS Med 2017;14:e1002467.

9 Hurst TE, Semrau K, Patna M, et al. Demand-side interventions for maternal care: evidence of more use, not better outcomes. BMC Pregnancy Childbirth 2015;15:297.

10 Hounton S, Byass P, Brahima B. Towards reduction of maternal and perinatal mortality in rural Burkina Faso: communities are not empty vessels. Glob Health Action 2009;2:2.

11 Manandhar DS, Osrin D, Shrestha BP, et al. Effect of a participatory intervention with women's groups on birth outcomes in Nepal: cluster-randomised controlled trial. Lancet 2004;364:970-9.

12 Hounton S, Chapman G, Menten J, et al. Accessibility and utilisation of delivery care within a skilled care initiative in rural Burkina Faso. Trop Med Int Health 2008;13 Suppl 1:44-52.

13 Blanchard AK, Prost A, Houweling TAJ. Effects of community health worker interventions on socioeconomic inequities in maternal and newborn health in low-income and middle-income countries: a mixed-methods systematic review. BMJ Glob Health 2019;4:e001308.
14 Gram L, Fitchett A, Ashraf A, et al. Promoting women's and children's health through community groups in low-income and middle-income countries: a mixed-methods systematic review of mechanisms, enablers and barriers. BMJ Glob Health 2019;4:e001972-17.

15 Rifkin SB. Examining the links between community participation and health outcomes: a review of the literature. Health Policy Plan 2014;29 Suppl 2:ii98-106.

16 Van Belle S, Rifkin S, Marchal B. The challenge of complexity in evaluating health policies and programs: the case of women's participatory groups to improve antenatal outcomes. BMC Health Serv Res 2017;17:687.

17 WHO. WHO recommendation on community mobilization through facilitated participatory learning and action cycles with women's groups for maternal and newborn health. Geneva: WHO, 2014.

18 Andersson N. Participatory research-A modernizing science for primary health care. J Gen Fam Med 2018;19:154-9.

19 Israel BA, Schulz AJ, Parker EA, et al. Review of community-based research: assessing partnership approaches to improve public health. Annu Rev Public Health 1998;19:173-202.

20 Ledogar RJ, Arosteguí J, Hernández-Alvarez C, et al. Mobilising communities for Aedes aegypti control: the SEPA approach. BMC Public Health 2017; 17:403.

21 Statistics UBo. National population and housing census 2014. Kampala, Uganda, 2016.

22 Schaaf M, Topp SM. A critical interpretive synthesis of informal payments in maternal health care. Health Policy Plan 2019;34:216-29.

23 Özesmi U, Özesmi SL. Ecological models based on people's knowledge: a multi-step fuzzy cognitive mapping approach. Ecol Modell 2004;176:43-64.

24 Giles BG, Findlay CS, Haas G, et al. Integrating conventional science and Aboriginal perspectives on diabetes using fuzzy cognitive maps. Soc Sci Med 2007;64:562-76.

25 Cockcroft A, Omer K, Gidado Y, et al. The impact of universal home visits with pregnant women and their spouses on maternal outcomes: a cluster randomised controlled trial in Bauchi state, Nigeria. BMJ Glob Health 2019;4:e001172.

26 Open data kit. open data kit, 2018. Available: https://opendatakit.org/ [Accessed 27 Aug 2018].

27 Buchanan A, O'Neill M. Inclusion and diversity: finding common ground for organizational action. A Deliberative dialogue guide. Canadian Council for International Cooperation, 2001.

28 Dart J, Davies R, A Dialogical DR. A Dialogical, Story-Based evaluation tool: the most significant change technique. Am J Eval 2003;24:137-55.

29 Davies R, Dart J. The most significant change (MSC) technique. A guide to its use, 2005

30 Software Yed. Available: https://www.yworks.com/products/yed

31 Andersson N, Beauchamp M, Nava-Aguilera E, et al. The women made it work: fuzzy transitive closure of the results chain in a dengue prevention trial in Mexico. BMC Public Health 2017;17:408.

32 Andersson N, Silver H. Fuzzy cognitive mapping: an old tool with new uses in nursing research. J Adv Nurs 2019;75:3823-30.

33 Gabrysch S, Campbell OMR. Still too far to walk: literature review of the determinants of delivery service use. BMC Pregnancy Childbirth 2009;9:1-18.

34 Bohren MA, Hunter EC, Munthe-Kaas HM, et al. Facilitators and barriers to facility-based delivery in low- and middle-income countries: a qualitative evidence synthesis. Reprod Health 2014:11:1-28.

35 Reich MR, Harris J, Ikegami N, et al. Moving towards universal health coverage: lessons from 11 country studies. Lancet 2016;387:811-6.

36 Hunter BM, Murray SF. Demand-side financing for maternal and newborn health: what do we know about factors that affect implementation of cash transfers and voucher programmes? BMC Pregnancy Childbirth 2017;17:262.

37 Bohren MA, Tunçalp Özge, Miller S. Transforming intrapartum care: Respectful maternity care. Best Pract Res Clin Obstet Gynaecol 2020;67:113-26

38 Tokhi M, Comrie-Thomson L, Davis J, et al. Involving men to improve maternal and newborn health: a systematic review of the effectiveness of interventions. PLoS One 2018;13:e0191620.

39 Gopal P, Fisher D, Seruwagi G, et al. Male involvement in reproductive, maternal, newborn, and child health: evaluating gaps between policy and practice in Uganda. Reprod Health 2020;17:114

40 Ruane-McAteer E, Gillespie K, Amin A, et al. Gender-transformative programming with men and boys to improve sexual and reproductive health and rights: a systematic review of intervention studies. BMJ Glob Health 2020;5:e002997.

41 Morrison J, Osrin D, Alcock G, et al. Exploring the equity impact of a maternal and newborn health intervention: a qualitative study of 
participatory women's groups in rural South Asia and Africa. Int J Equity Health 2019;18:55.

42 Gram L, Desai S, Prost A. Classroom, Club or collective? three types of community-based group intervention and why they matter for health. BMJ Glob Health 2020;5:e003302.

43 Crankshaw TL, Kriel Y, Milford C, et al. "As we have gathered with a common problem, so we seek a solution": exploring the dynamics of a community dialogue process to encourage community participation in family planning/contraceptive programmes. BMC Health Serv Res 2019;19:710.

44 Abubakar A, Shallwani S, Wanjala SW. Community Dialogues as a Strategy for Identifying and Addressing Child Protection Needs in Shinyanga, Tanzania. In: Verma S, Petersen AC, eds. Developmental science and sustainable development goals for children and youth. Cham: Springer International Publishing, 2018: 187-206.

45 Martin S, Leitão J, Muhangi D, et al. Community dialogues for child health: results from a qualitative process evaluation in three countries. J Health Popul Nutr 2017;36:29.
46 Gilson L. Trust and the development of health care as a social institution. Soc Sci Med 2003;56:1453-68.

47 Kruk ME, Freedman LP, Anglin GA, et al. Rebuilding health systems to improve health and promote statebuilding in post-conflict countries: a theoretical framework and research agenda. Soc Sci Med 2010;70:89-97.

48 Ormel I, Salsberg J, Hunt M, et al. Key issues for participatory research in the design and implementation of humanitarian assistance: a scoping review. Glob Health Action 2020;13:1826730

49 Afifi RA, Abdulrahim S, Betancourt T, et al. Implementing community-based participatory research with communities affected by humanitarian crises: the potential to Recalibrate equity and power in vulnerable contexts. Am J Community Psychol 2020;66:381-91.

50 Barker KM, Ling EJ, Fallah M, et al. Community engagement for health system resilience: evidence from Liberia's Ebola epidemic. Health Policy Plan 2020;35:416-23. 